\title{
Relationship Between Socio-demographic Variables and Social Distance Towards the Mentally III
}

\author{
Chukwujekwu Chidozie Donald ${ }^{1, *}$, Chukwujekwu Chioma Judith², \\ Olose Emmanuel Omamurhomu ${ }^{3}$ \\ ${ }^{1}$ Department of Neuropsychiatry, University of Port Harcourt Teaching Hospital, Port Harcourt, Nigeria \\ ${ }^{2}$ Department of Educational Management, University of Port Harcourt, Port Harcourt, Nigeria \\ ${ }^{3}$ Department of Psychiatry, University of Calabar, Calabar, Nigeria
}

Email address:

chidozie.chukwujekwu@uniport.edu.ng (Chukwujekwu C. D.)

${ }^{*}$ Corresponding author

\section{To cite this article:}

Chukwujekwu Chidozie Donald, Chukwujekwu Chioma Judith, Olose Emmanuel Omamurhomu. Relationship Between Socio-demographic Variables and Social Distance Towards the Mentally Ill. American Journal of Psychiatry and Neuroscience. Vol. 4, No. 3, 2016 , pp. 52-56. doi: 10.11648/j.ajpn.20160403.14

Received: April 30, 2016; Accepted: May 10, 2016; Published: May 26, 2016

\begin{abstract}
This prospective study was designed to identify if there is any relationship between socio-demographic variables and social distance towards the mentally ill. It was carried out at the Madonna University Teaching Hospital over a 10 month period. Two hundred and sixty nine consenting subjects were enlisted in the study. However, only 254 completed it. The 254 subjects comprise 87 males (34.3\%) and 167 females (65.7\%). The minimum MBSDS score of 7 and the maximum of 35 were recorded in the study. It was established that there is significant association between literacy and MBSDS score. Literate subjects showed lesser MBSDS score compared to illiterate ones. Younger patients (less than 45yrs old) showed higher MBSDS scores on the average compared with older patients. The cause, management and eventual outcome of a patient's mental illness are greatly hampered by social stigma. Sustained public education and sustained advocacy against stigma towards the mentally ill cannot be overemphasized.
\end{abstract}

Keywords: Socio-demographic, Relationship, Mentally Ill, Stigma

\section{Introduction}

From time immemorial, mentally ill people have been met with a great deal of rejection. Despite outstanding breakthroughs in science and technology as well as increased knowledge of the brain and human behaviour, the mentally ill still suffer much stigmatization and rejection even in our modern world. Stigma can be defined as a sign of disgrace, which sets a person apart from others [1]. Stigma assault with mental illness has been strongly associated with suffering, disability and poverty [1].

Public prejudice and social distance towards mental illness have impeded early treatment and early recovery of the psychiatric patients through optimal utilization of mental health services [1-4]. In recent years, several programs have been initiated to reduce stigma and discrimination related to mental illness [6-9].
While some studies posit that personal beliefs and attitudes towards mental illness are related to individual characteristics and surrounding regional context [5], there's paucity of report on the relationship between socio-demographic variables and social distance towards the mentally ill. The study therefore aims to identify the socio-demographic variables that make one more vulnerable to be socially distant towards the mentally ill.

Knowledge of the socio-demographic features of those who stigmatize the mentally ill will help identify the category of people that should be the focus of our anti-stigma campaign if stigma towards the mentally ill is to be reduced to the barest minimum.

\section{Materials and Methods}

The prospective, cross sectional study was conducted at 
Madonna University Teaching Hospital, Elele in Rivers State, Nigeria within a period of 10 months.

\subsection{Instruments}

For this study, the instruments employed were as follows:-

1. The modified Bogardus Social Distance Scale (Modified BSDS).

2. A self-designed, semi-structured, self administered questionnaire containing psychiatric illness variables.

The Bogardus social distance scale is a psychological testing scale created by Emary S. Bogardus to empirically measure people's willingness to participate in social contacts of varying degrees of closeness with members of diverse social groups such as racial and ethnic groups. The scale asks people the extent to which they would be accepting of each group (a score of 1.00 for a group is taken to indicate no social distance) [10].

For this study, the modified version of Bogardus Social Distance Scale (MBSDS) developed by Link [11, 12, 13] was used. The MBSDS was presented in a likert form. Questions asked include:- How would you feel having the mentally ill presented as

1. Your Landlord

2. Your co-worker

3. Your neighbor

4. Your friend

5. Business Associate

6. In - law

7. Child care provider

For each of these questions, there are 5 options (Likert Format) from which the subject is expected to choose one with its corresponding score:-

\begin{tabular}{|c|c|}
\hline In any case & Score 1 \\
\hline Maybe but I have my reservation & 2 \\
\hline aybe but with definite condition & - \\
\hline Difficult to accept but maybe & \\
\hline In no case at all & \\
\hline
\end{tabular}

A score of 1 indicates no social distance

A score of 5 indicate maximum social distance.

The reliability of the scale, assessed by means of Cronbach's alpha is 0:9 [11]

Before the commencement of this study, informed consent was obtained from all the subjects. Two hundred and sixtynine (269) subjects enlisted in the study but only two hundred and fifty-four (254) completed it. The two hundred and fiftyfour (254) subjects comprise 110 relations of the mentally ill, 47 health workers and 97 non-relations. A relative of every other psychiatry patient who attended the psychiatric clinic within the stated period participated in the study.

The health workers and non-relatives of the mentally ill were selected randomly. The two questionnaires specified above were administered to each subject. The total score of the modified BSDS was calculated for each subject.

\subsection{Data Analysis}

The Data was analyzed using statistical package for social sciences (SPSS) version 20at 5\% level of significance and $95 \%$ confidence interval. Frequency distribution charts were employed to access the various socio-demographic variables and the score of the Modified Bogardus social distance scale. One way Analysis of variance (ANOVA) was used to test for significance among various groups. Contingency test were carried out using chi-square test for categorical variables.

\section{Results}

Table 1. Age and Bogardus Score.

\begin{tabular}{lll}
\hline Age (year) & Number (\%) & Average MBSD Score \\
\hline $15-24$ & $45(17.7)$ & 26.8 \\
$25-34$ & $77(30.3)$ & 27.1 \\
$35-44$ & $37(14.6)$ & 25. \\
$45-54$ & $75(29.5)$ & 22.9 \\
$55-64$ & $18(7.1)$ & 23.4 \\
$>65$ & $2(.8)$ & 31. \\
Total & $254(100.0)$ & \\
\hline
\end{tabular}

Age \& Bogardus scores: $-X^{2}=6090.8, d f=23, p>0.05$.

There is no significant association between age and Bogardus scores.

Table 2. Sex and Bogardus Score.

\begin{tabular}{lll}
\hline Sex & Number (\%) & Average MBSD Score \\
\hline Male & $87(34.3)$ & $24.9 \pm 5.8$ \\
Female & $167(65.7)$ & $25.9 \pm 6.9$ \\
Total & 254 & \\
\hline
\end{tabular}

$X^{2}=7.874, d f=23, p>0.05$.

There is no significant association between gender and Bogardus scores.

Table 3. Education Level and Bogardus Score.

\begin{tabular}{lll}
\hline & Number $(\%)$ & Average MBSD Score \\
\hline Primary & $31(12.2)$ & $27.8 \pm 5$ \\
Secondary & $56(22)$ & $25.8 \pm 4$ \\
Tertiary & $146(57.6)$ & $23.1 \pm 6$ \\
Missing & $21(8.3)$ & \\
Total & 254 & \\
\hline
\end{tabular}

$X^{2}=18.554 d f=23, p>0.05$.

There is no significant association between educational level and Bogardus scores.

Table 4. Religion and Bogardus Score.

\begin{tabular}{lll}
\hline Religion & Number (\%) & Average MBSD Score \\
\hline Roman Catholic & $195(76.8)$ & $24.7 \pm 6.6$ \\
Pentecost & $29(11.4)$ & $27.2 \pm 6.7$ \\
Orthodox Protestant & $17(6.7)$ & $27.6 \pm 6$ \\
Aladura/ traditional Church & $7(2.8)$ & $27.1 \pm 4$ \\
Others & $3(1.2)$ & \\
Total & 254 & \\
\hline
\end{tabular}

$X^{2}=23.921 d f=23 ; p>0.05$.

There is no significant association between religion and Bogardus scores.

Table 5. Literacy and Bogardus Scale.

\begin{tabular}{lll}
\hline Literacy & Number $(\%)$ & Average MBSD Score \\
\hline Literate & $216(85.0)$ & $22.4 \pm 6.9$ \\
Illiterate & $36(14.2)$ & $25.8 \pm 8.7$ \\
Missing & $2(.8)$ & \\
Total & 254 & \\
\hline
\end{tabular}

$X^{2}=5.156 d f=23, p<0.05$. 
There is significant association between literacy status and Bogardus scores. Out of the hundred and sixty-nine (269) subjects who were enlisted in the study, 254 completed it; [87 males (34.3\%) and 167 females (65.7\%)] fifteen subjects were therefore excluded from the study. The minimum MBSDS score of 7 and the maximum score of 35 were recorded in the study. The average MBSDS score for all subjects is $25.3 \pm 6.5$

Table 1 shows the age distribution of the patients and their average MBSDS score. The mean age of the 254 subjects is $37.7 \pm 12$ [that of males $36.12 \pm 12$ and that of female $38.6 \pm$ 12]. In general, the younger patients (those below age 45) showed higher MBSDS score on the average compared with the older patients $(26.8,27.1,25.0)$ and $(22.0,23.4)$. There is no significant association between age and MBSDS scores $\left(X^{2}=609.8, d f=23, p>0.05\right)$.

On the average, females showed more social distance than the males toward the mentally ill $(25.5 \pm 6.9$ vs $24.9 \pm 5.8)$ but the association between gender and Bogardus scores is not statistically significant. $\left(X^{2}=7.874, d f=23, p>0.05\right)$. Compared to other christian denominations, the Roman Catholics showed the least form of social distance on the average $(24.7 \pm 6.6)$, while the Orthodox protestant showed the greatest degree of social distance $27.6 \pm 6$ (table 3 ). Nevertheless there is no significant association between denomination and MBSDS score $\left(X^{2}=23.92, d f=23, p>\right.$ $0.05)$.

The illiterate subjects $(36,14.2 \%)$ had higher MBSDS $(25.8 \pm 8.7)$ than the literate ones $(216,85.0 \%), 22.4 \pm 6.9$. There is a significant association between literacy status and MBSDS score $\left(X^{2}=5.156, d f=23, p<0.05\right)$. Similarly, subjects with primary education had the highest MBSDS $(27.8 \pm 5)$, while those with tertiary education had the least MBSDS $(24.9 \pm 6)$, but there is no significant association between level of education and MBSDS. (See table 3).

\section{Discussion}

The course management and eventual outcome of a patient's mental illness is greatly hampered by social stigma. Furthermore, social distance towards the mentally ill is widely endorsed by the general public. Studies show that stigmatization attitudes cut across cultures [14, 15, 16]. Nevertheless there's paucity of work on this subject in the underdeveloped world, unfortunately ignorance and myth solely based on tradition and superstition have affected negatively the proper handling of patients in this part of the world. [17]

Using MBSDS, the minimum social distance one can have toward the mentally ill is 7. This is because score of lindicatesno social distance; hence a total score of 7 for the 7domains of the MBSDS. The maximum possible social distance is 35 (i.e maximum social distance in the 7 domains).

From the study, the average MBSDS score of all the subjects is $26.3 \pm 6.9$. This represents $71.4 \%$ of the maximum score possible in the MBSDS. If we regard $0-33 \%$ as low social distance, $34-66 \%$ as moderate social distance and $67-$ $100 \%$ as severe social distance, we can clearly state that in this study on the average, the subjects exhibited severe social distance towards the mentally ill.

This study demonstrates that younger subjects below the age of 45 showed higher social distance scores on the average compared with older subjects but the association between age and the social distance scores was not found to be statistically significant. This finding is at variance with some earlier studies carried out in the developed world [18, 19, 20]. These studies posit that younger people were less prejudiced than the older ones towards the mentally ill. It appears as if prejudicial attitudes which influence discriminating behaviour alters with age. Further research needs to determine whether this is more as a result of biological changes that occur with aging or social contacts experience and general attitude to life issues that also alter as one grows older.

From the study, even though more females exhibited more social distance than males, the difference is not statistically significant. This is in consonance with other studies done elsewhere. Studies done to ascertain the relationship between the level of education and attitude of social distance towards the mentally ill persons yielded conflicting information. While some studies indicated that people with lower level of education exhibited higher social distance towards the mentally ill, others reported that people exhibited similar attitudes towards the mentally ill irrespective of their level of education $[21,22]$.

A study done by Jim Crabb et al [23], reported that there was no significant difference in stigmatizing beliefs based on education. This study showed that literate subjects were more tolerant towards the mentally ill than the illiterate subjects and the difference between the two means of social distance scores for both categories are statistically significant. Furthermore, the subjects with the least education (primary) had the highest average of MBSDS score, while those with tertiary education had the least. Nevertheless the score of 24 still translates to moderate social distance towards the mentally ill which is significant. Even though the difference between the mean scores for the various categories based on educational level is not statistically significant, the trend towards being more socially distant towards the mentally ill when one is less educated is amply demonstrated in this study. This underscores the importance of literacy and education, in dissolving myths, ignorance, misconception and primordial assumptions that fuel the prejudice and stigma towards the mentally ill.

Advocacy for the mentally ill should be targeted more towards the illiterate and the younger generation. This becomes more imperative when one considers the great percentage of sub-Saharan Africa that is illiterate. Furthermore, our religious leaders should be carried along if significant progress in the campaign against stigma towards the mentally ill is envisioned in the long run.

This study was carried out in a Catholic University Teaching Hospital, hence the larger percentages of the cohort 
(76.8\%) are Roman Catholics. Even though there's no significant association between denomination types and MBSDS scores, the distribution of the scores showed that there is moderate to severe social distance across all the denomination studied. Hence there is need to significantly carry our religious leaders along in the fight against the mentally ill.

Furthermore, even though calls by some researchers to rename some psychiatric disorders in order to change public beliefs and attitudes towards the mentally ill remains controversial [24, 25], the expected advantages of reduced stigma and an improved communication between clinicians, patients and families as proposed by the proponents $[26,27]$ of this initiative are too weighty to ignore. Hence a more adept consideration of this initiative should be considered.

\section{Conclusion}

The cause, management and eventual outcome of a patient's mental illness is greatly hampered by social stigma. Literacy is a key socio-demographic variable that can sway one's attitude positively towards the mentally ill and hence reduce social distance. The trend towards being socially distant towards the mentally ill when one is less educated was also clearly demonstrated in ithis study. Therefore, the need for governments of nations in sub- Saharan Africa to entrench policies that will encourage mass literacy of the general public cannot be overemphasized. Similarly, sustained public education and advocacy againststigma towards the mentally ill is imperative.

\section{Limitations}

One of the limitations of this study is that the responses of the subjects to the questions on how socially distant they are towards the mentally ill are subjective. It is not certain whether their response for a particular patient reflects the true feeling of the public towards all mentally ill persons at all times or whether there response would vary with respect to the particular diagnosis with which the patient is labeled. Furthermore the cohort was drawn from a Catholic University, hence result may not be applicable the general population.

\section{References}

[1] El-Adi M., El-Mahdy M, Avis M. First Episode Psychosis (FEP): factors associated with delayed access to care in a rural Egyptian setting. Eur. Psychiatry. 2007; 22 (suppl 1): 579-580.

[2] Jovanovic D. Duration of untreated Psychosis and stigma in psychotic patients: a family view. Eur. Psychiatry. 2007; 22 (suppl 1): 117-118.

[3] Lehtinen D, Vaeisaenen E. Attitudes towards mental illness and utilization of Psychiatric treatment. Soc. Psychiatry Epidemiol. 1978; 13 (2): 63-68.

[4] Kessler RC, Mickelson KD, Williams D R. The Prevalence,
Distribution and Mental Health correlates of perceived discrimination in the United States. J Health Soc Behav 1999; 40 (3): 208-230.

[5] Hyemgap J, Juan-Tae L, Juhiran O, Sean Young L, Yang-Ik K, Jin-Seok L. Factors Affecting Public Prejudice and Social Distance on Mental illness: Analysis of Contextual Effect by Multi-level Analysis; J Prev. Med. Public Health, Mar 2012; 45 (2); 90-97.

[6] Crisp A H. Changing Minds; every family in the land. An update on the college's campaign. Psychiatry Bull. 2000; 24: $267-8$.

[7] Lopez-Nbor Jr. J. The WAP and the fight against stigma because of mental illness. World Psychiatry 2002; 1: 30-31.

[8] Sartorius N. Fighting Schizophrenia and Stigma: A new WPA educational programme. Br. J. Psychiatry 1997; 170: 297.

[9] Angermeyer MC, Beck M., Diplsov, Matsclinger $H$. Determination of the Public's Preference for Social from people with Schizophrenia. Can J. Psychiatry 2003; 48: 10.

[10] Bogardus ES. Social Distance in the city. Proceedings and Publications of the American Sociological Society. 20, 1926; 40-46.

[11] Link BG, Cullen F. Reconsidering the social rejections of exmental patients: levels of attitudinal responses. A. J. Community 1983; 11 (26): 1-26.

[12] Bogardus ES. Measuring Social Distance. J Appl. Social 1925; 1 (2): 216-226.

[13] Vtatko P. Socio-demographic Characteristics of Secondary School Students and Social Distance towards National and Religious Groups. Drustrena Istrazivanja; Journal for General Social Issues 1996; 5 (6): 25-26.

[14] Greenly JR. Social Factors, Mental Illness and Psychiatric Care: Recent advances from a sociological perspective. Hospital and community psychiatry 1984; 35 (81): 3-820.

[15] Rablcin J. Public Alttitudes towards mental illness. A review of the literature. Schizophrenic Bulletin. 1974; 10: 9-33.

[16] Brokington IF, Hallp LJ, Murphy C. The Community Tolerance of the mentally ill. Br J Psychiatry 1993; 162: 9-99.

[17] Chukwujekwu DC, Stanley PC. Patterns of Aggression among Psychiatric in-patients at the Jos University Teaching Hospital. J Med Tropics 2008; 10 (1): 7-10.

[18] Bryne P. Stigma and Mental illness and ways of diminishing it. Adv. Psychiatry Treat 2000; 6: 65-72.

[19] Cerrigar PW, Watson A C. Understanding the impact of stigma on people with mental illness. WWW Psychiatry 2002; 1 (1): 16-24.

[20] Klin A, Lemish D. Mental disorder stigma in media: review of studies on production, content and influence. J Health Community 2008, 13 (5): 434-449.

[21] United States: Public Health Services. Office of the Surgeon General, Center for Mental Health Services US; United State Substance Abuse and Mental Health Services Administration in Mental Health: Culture, Race and Ethnicity: A Supplement to Mental Health: A representative of the Surgeon General, Department of Health and Human Services. US Public Health Services, Rockvile, MD; 2001. 
[22] Ayazi T, Lien L, Eide A, Shadar EJ, Hauff H. Community Attitude and Social Distance towards the mentally ill in South Sudan: A survey from a post-conflict setting with no mental health services. Soc. Psychiatry. Psychiatry Epidermal 2014; 49 (5): 771-780.

[23] Jim C, Rober C S, Demonbly K, Nel M, Sylvester C, Rajeer K. Attitudes towards mental illness in Malawi. A crosssectional survey. BMC Public Health 2012; 12: 54.

[24] Ellison N, Mason O, Scior K. Renaming Schizophrenia to reduce stigma; comparison with the case of bipolar disorder. Br J Psychiatry 2015; 206 (4): 341-342.
[25] Ellison N, Mason O, Scior K. Public beliefs about and attitudes towards bipolar disorder; testing theory based models of stigma. J Affect Disord 2015; 175: 116-123.

[26] Lasalvia A, Penta E, Sartorius N, Henderson S. Should the label "schizophrenia" be abandoned ? Schizophr Res 2015; 162 (1-3): 276-284.

[27] Imholf R. Zeroing in on the schizophrenia label on stigmatizing attitudes; a large scale study. Schizophr Bull 2016; 42 (2): 456-463. 